\title{
Traditional Saami Hunting in Relation to Drum Motifs of Animals and Hunting
}

\author{
By RolF KJELLSTRÖM
}

\section{Drum material}

It was intended that I should deal with traditional Saami hunting in relation to the animal and hunting motifs on their drums To begin with the latter, I have limited my material to southern Saams drums, i e nos 1-4, 6-42 and no 46 in Manker's list (Manker 1950) This makes a total of 42 drums, or just over half of those known The reason I have limited myself to these is because it is possible to compile statistics for the position of anımals on these drums, since the drums in question are fairly uniform in appearance, with a rhombus in the middle, from which there emerge four lines Schematically, these drums can be divided into four fields, of which I have chosen to call the top left-hand one no 1 , the top right hand one no 2, the lower left-hand one no 3 and, finally, the lower right hand one no 4 It was hoped that such a division, with statistics, would help in the interpretation of the drum's symbolism (Figs 1,2)

\section{Previous literature}

In matters regarding traditional Saamı hunting, we do not, unfortunately, have very much information about the southern Saamı terr tory From the period in question - $1 \mathrm{e}$ the time when the drums originated - we do not have very extensive material of any kind Moreover, the material we have is only relevant for the area from which the information was taken, since Saami culture has assumed such varied forms - both chronologically and regionally - that it would be more appropriate to talk of Saamı cultures rather than a single Saami culture This lack of suitable source materal obliges me, therefore, to speak of things with which we are not very familiar

If we return to early accounts, it is only really Niurenius among the 17 th sources used by Schefferus - and to a certain extent, Grahn and Lundius - who deal with southern Lapland Niurenius writes 


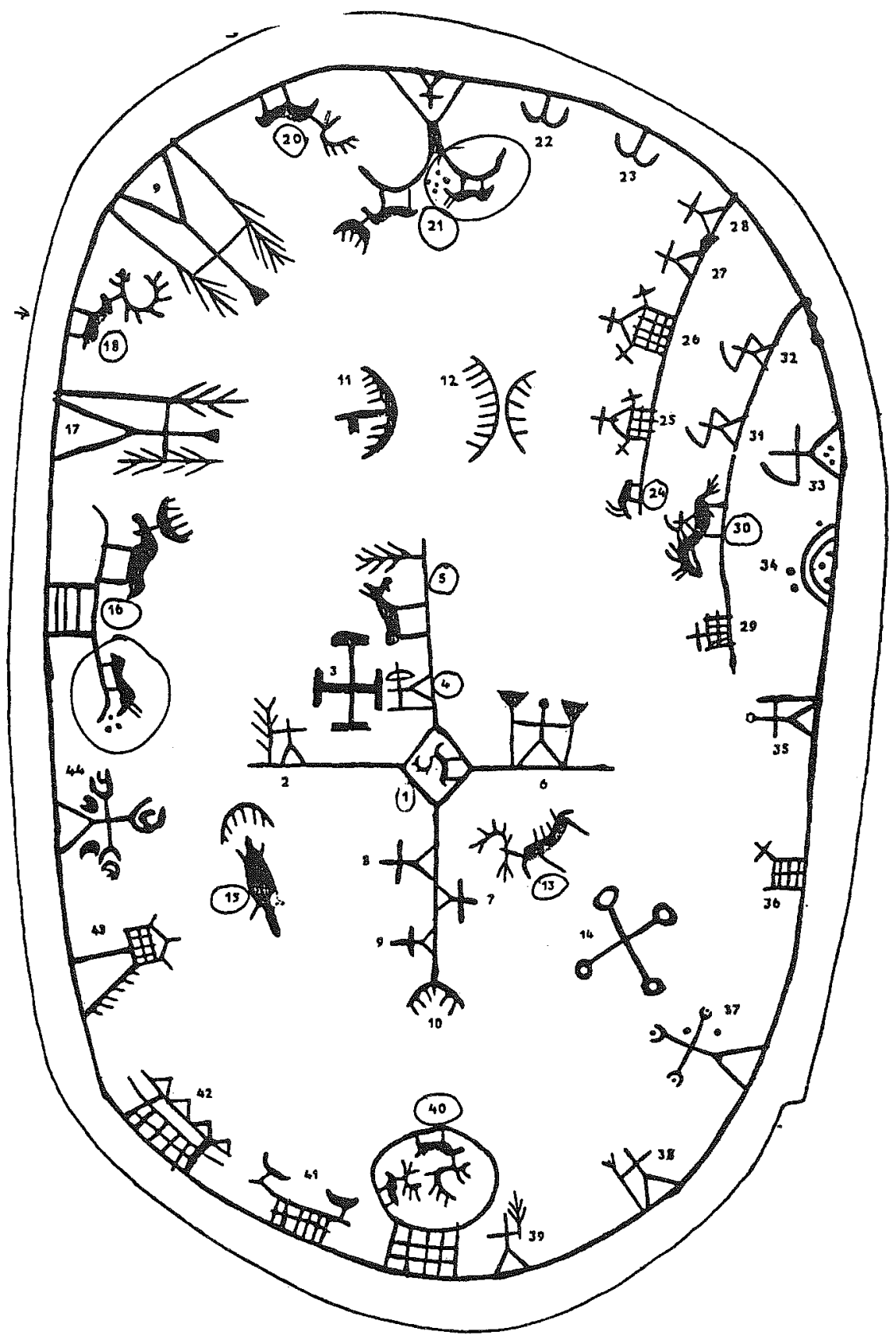

Fig 1 Southern Saamı drum from Lycksele Lapp reservation, 17th century Nordiska Museet 
Fig 2 Diagram of the southern Saaml drum

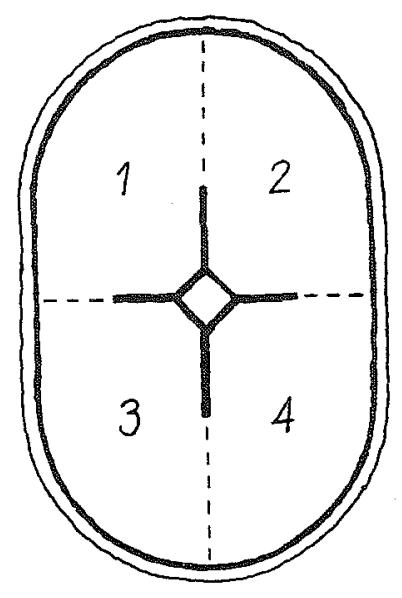

of Ume lappmark, as do Grahn and Lundius, but the latter also consider conditions in Lule lappmark Then in the 18th century comes Linnaeus, but his experience of the southern lappmarks is strictly limited and his observations are relevant primarily for Lule lappmark

During the 19th century there are several authors whose writings deal with the Saamıs, for example Zetterstedt and Laestadius, but there is unfortunately little reference to the actual southern lappmarks (Zetterstedt 1980) More valuable here is Sigfrıd Drake's book Västerbottenslapparna [The Lapps of Västerbotten], based in part on notes by the Reverend Nensén Of very great value, too, are the memoirs of Kristoffer Sjulsson, which go back to the first half of the 19th century Drake 1918; Pettersson 1979)

Then in the 20th century - in 1910 to be precise - comes Sven Ekman's extraordinary study of hunting and fishing in Norrland This work also takes into account the older literature already mentioned (Ekman 1910)

In recent times there are a number of studies, but I should like to draw attention to the work of my colleague, Heidi Henriksson, on popular huntıng and fishıng in Norrland (Henriksson 1976)

As I suggested earlier, however, we are forced to admit that the material dealing with huntıng among the southern Saamis is extremely thin, particularly if we limit ourselves to the perrod of origin - or should we rather say the assumed period of origin - of the Saams drums

Dunng the 18th and 19 th centuries there were no major variations either One may claim that the greatest difference lay in a hunting method, namely the one so often used of pursuit on skis 


\section{Preservation of the hunting method}

There seems to be another fundamental aspect to hunting in the lappmarks, $1 \mathrm{e}$ many of the huntıng and trapping methods practised have survived over a long period of time and have a long history and tradition behind them Admittedly, the introduction of firearms etc has brought about certain changes in hunting patterns, but as far as the traditional Saami hunts are concerned - for predators, for exam ple - such innovations have not noticeably changed traditional Saamı methods of hunting Right into the 20th century, the hunting of such predators as lynxes, wolves and wolverines, for example, was carried out in the form of a chase with the stick spear as the only weapon This was regarded as being the most effectıve one (Kjellström 1989)

If the above arguments are true, this means firstly that we have access to a larger amount of material, since we are able to include the hunting of the Saamis and that of other country people in the same category, although this doesn't actually help us very much with regard to the early material; and secondly, that in chronological terms we can regard material gathered later as relevant for perıods much earlier in time, and not limit ourselves exclusively to the period covered by the account

\section{Problems of interpretation}

If we now attempt to compare hunting in the historical reality of the Saamis with the picture provided by the southern Saamı drums, I shall work primarily from the anumals we can identify on these drums Before I begin to interpret pictures, however, I should like to mention certain general experiences I have had in connection with this study

One may wonder if it is possible for anyone to interpret a picture unconditionally One has a certain ground of one's own to stand on and the question arises of whether this is the correct position, when as in the present case - we approach another culture We naturally include the experiences of our own culture in interpretations of another culture Even if we try, in different ways, to adopt the point of view of another culture, we are nevertheless obliged to struggle continually with our own cultural background

How are we to interpret reindeer horns, for example? (Fig 3). Do they represent living reindeer or merely reindeer horns, or are they quite simply symbols for both of these things together, or rather for everything connected with a reindeer? I myself don't know 
Fig. 3 Rendeer horns

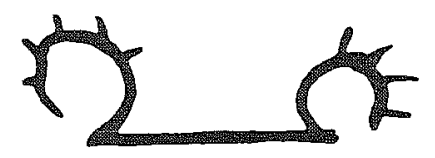

Another problem is that of actual drawing skill and the stylistic element If I were asked to draw an anımal, for example, I am very uncertain as to how others would interpret it

One difficulty with the interpretation of pictures is that we characterize an ambiguous animal as a clearly identifiable one, if th happens to appear in the place on the drum where we have previously been able to establish with complete certanty that the animal occurs Take a horse, for example, which normally appears in the top right hand corner $A$ source of error is that one believes that a hard-to identify anımal is a horse, if it turns up in the same place on the drum Another similar example is provided by the animal in the rhombus in the middle of the southern Saami drums It is often a reindeer, we can see, but on the other hand it is sometimes difficult to decide what the animal in question is, although in these cases, too, it is tempting to assume that it is a reindeer

In a number of cases I have tried testing my informants with respect to animals which are hard to identify, and it has proved difficult to obtain a uniform result

I am not trying to suggest that I have avolded errors like those I have discussed above, but I mention them because they exist for me as for everybody else Naturally, it must help if one is on the look-out for them In the following, therefore, I have chosen to present only those interpretations of drums of which I am fairly certain

\section{Animals and hunting}

\section{Reindeer hunting}

The animal that seems most appropriate to begin with is the reindeer, which is the commonest species of animal on the southern Saami drums

Traditionally, the reindeer has occurred partly in the wild and partly in a domesticated variety. Wild reindeer more or less disappeared from the southern lappmarks in the first half of the 18th century, according to Ekman, but this does not exclude the possibility that wild resndeer were shot later in the same century and even into the 19th century Above all, there may have been a few wild rendeer left in the fells Otherwise one may probably assume that the reindeer which were shot 
later were actually domesticated reindeer that had gone wild, which is another matter (Ekman 1910, 16)

Niurenıus mentıons several ways in which the Saamıs hunted reindeer at the beginning of the 17th century, and Lundius describes conditions in the 1660's and 1670's, where he mentions the lure for the reindeer of the great forest bogs, which gave rise to hunts by the forest Saamis in these places (Niurenius 1905, 17, Lundius 1905, 11) From Lycksele lappmark it is also mentioned that the forest Saamis often let the fell Saamis "glide after reindeer" in the 1670's It was in the interests of the reindeer owning Saamıs that the wild reindeer disappeared, since they could make domesticated reindeer feel restless and even go wild

It is clear, according to Ekman, that wild reindeer were common in the 1650's and later in certain southern Saamı areas (Ekman 1910, $8 \mathrm{f}$ )

Some of the hunting methods used included stalking, where the hunter tried to get into a certain position in relation to his prey It was doubtless customary to seek out the passes traditionally used by reindeer This kind of hunting must have been particularly effective when it was combined with battue, so that some hunters drove the reindeer in an agreed direction whilst others were detailed to stand at a pass Different kinds of side fencing were used on these occasions, and there was one special kınd of huntıng called vuobma, which meant precisely fence Hunting with pits was certainly enhanced by the fact that the reindeer were driven on so they became nervous, as a result of which they were forced to make rapid - and for them perhaps fatal - choices of direction The driving of reindeer could also be directed towards a natural ravine or something similar

Hunting with a tame reindeer as decoy was mentioned by Ottar, as we know, in the early part of the 19th century Even if this source refers to a completely different area, there is reason to assume that the method in question was practised in all lappmarks

Traps were also set, in which the reindeer fastened by their antlers Amongst other places, this is known from Lycksele lappmark

In addition there was a kind of shoot in Lycksele lappmark, the so called reindeer drive

For weapons, bows and arrows were probably very important Spears could also be used in certain situations

At the same tıme as reindeer were hunted, the Saamis also had domesticated animals Doubtless the Saamis for a long time had numbers of tame reindeer, used to entice wild reindeer, to pull loads and perhaps also to provide milk 
Reindeer on the Drums (Fig 4)

The reindeer is the most frequently recurring animal on the drums and is found pictured on almost all the southern drums except two, where figures of reindeer horns nevertheless appear It is possible, as suggested above, that certain horn pictures should be interpreted as reindeer, but I have chosen in the following account to start from clearly portrayed animals

The reindeer is often excellently characterized in a simple form It is easy to see that it is above all the male reindeer - perhaps the wild male reindeer - that has captured the artist's interest, with the antlers drawn in an impressive manner Reindeer cows and calves are not portrayed to anything like the same extent There aren't any large herds occurring on the drums elther, but two or three figures are then made to suggest the herd

In the centre of the southern Saamı drums - in the actual rhombus - there are clearly defined reindeer in 11 cases

Often the reindeer figures stand alone on one of the three upper rays of the sun figure, or on the left-hand edge of the drum but rarely on the right-hand side, or floating freely in the middle of the picture surface

All in all, there are a total of 349 clearly drawn reindeer figures As regards their position in the four distinct main fields, I have found in the centre: 11 figures; in field no 1 118; in field no 2 : 52 ; in field no $3: 104 ;$ in field no $4: 64$

If we divide the drum into a left hand and a right-hand side, we see that the left half has 222 figures and the nght half 116 There are thus roughly double the number of rendeer figures on the left-hand side compared to the right

It is interesting to establish to what extent and where on the drum domestic reindeer occur Manker has described a number of com binations of figures, where he suggests that domestic reindeer are involved: for example, when the reindeer have been drawn near figures suggesting a settlement etc For my own part, I have found several Iron Age sites in the Swedish fells, where it has emerged quite clearly that the inhabitants of the settlement had lived very close to trapping areas for wild reindeer, so I would not dare to share Manker's interpretation in this particular case Another element in the figures where I have not adapted Manker's interpretation, either, concerns what Manker regards as a reindeer enclosure, and which occurs on the Asele drums I believe that Manker's interpretation may very well be correct, but 

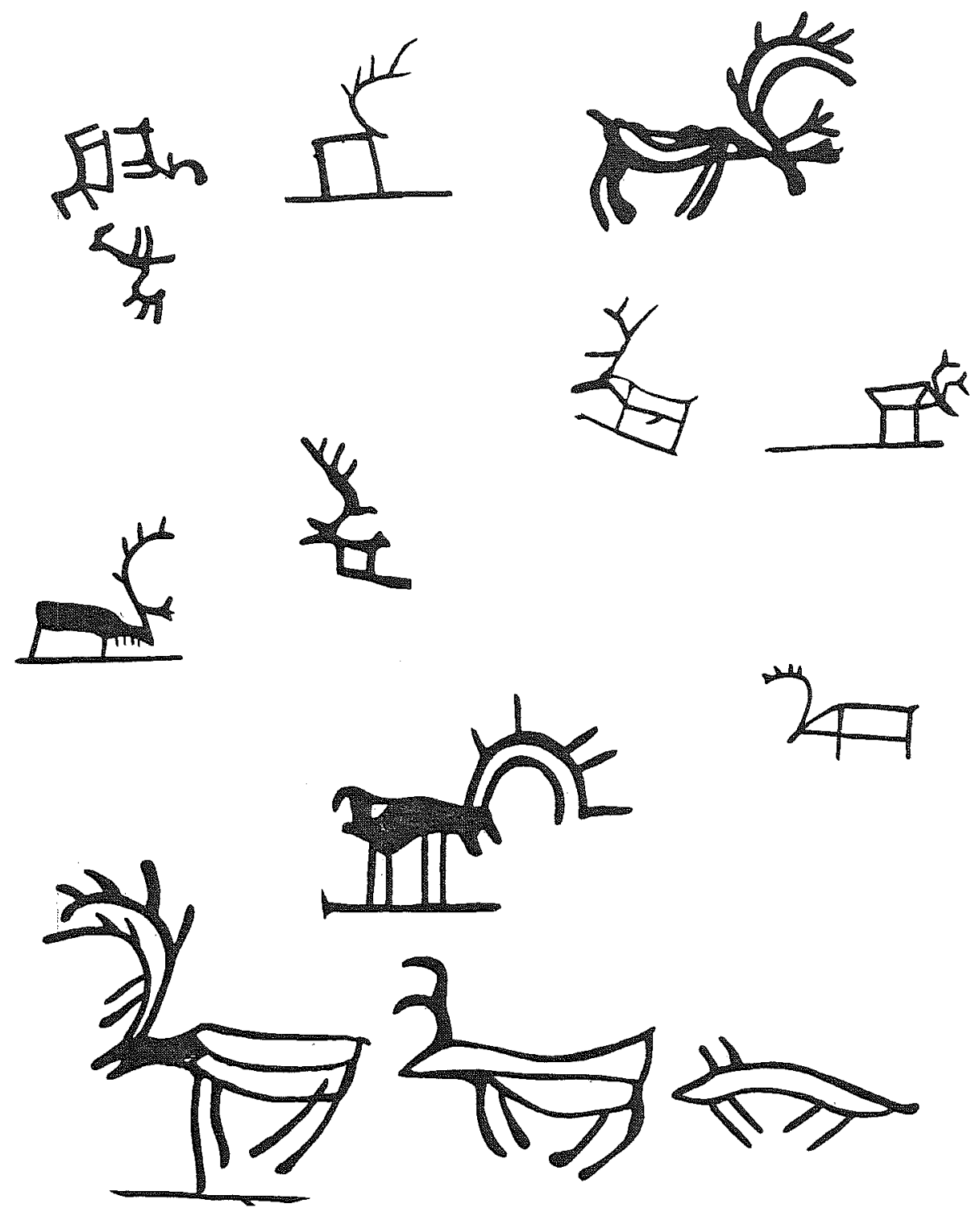

Fig 4 Reindeer figures. 
as it happens to be the case that constructions similar to reindeer enclosures were also used in hunting wild reindeer, I have not wished to commit myself to the same interpretation as Manker

For my own part, I have only been willing to regard the figure as a tame reindeer when one sees the reindeer figure in front of a sledge (Fig 5) We have 13 clear cases of this in the material, distributed over three of the drum's fields - but not however in field number 3

I have not been able to identify any milking scene

We will leave the reindeer by pointing out that, of the more than 600 figures I believe I have identified on the southern Saamı drums, over half of them or, more precisely, $58 \%$ are reindeer

\section{Elks}

\section{Elk hunting}

The elk has been, and still is, an important quarry, occurring in the rich traditional lore of the Saamis, where it also constitutes one of the Saami constellations

The strange thing about the elk is that it disappeared from the lappmarks for a time - at least from the southern ones - to return around the 1860's Whether the presence of the elk varied as much in former times as it has done in the last 100 years is something we do not know for certain But we do know that, for a long time previously, the elk had been an important quarry Hunting with a dog doubtless played a part at a farrly early stage, whether it was allowed to run loose or kept under control Stalking was also practised with this animal, although - as distinct from the reindeer - the elk is not a gregarious animal (except in the winter) and so the drive probably didn't produce the same results as this method of hunting did for reindeer.

Pursuit on skis was very important It was necessary to find a trail, approach the animal and then - when one got close to it - move at top speed In deep snow and with a hard frozen crust it was very tiring for the elk and eventually painful, too, when the sharp crust to began to lacerate the elk's legs This method had a devastating effect on the elk population, since a skilful and persistent skier could catch the elk after half a day

Of other methods for catching elks we may mention p1ts, together with so-called elk baits and shooting 


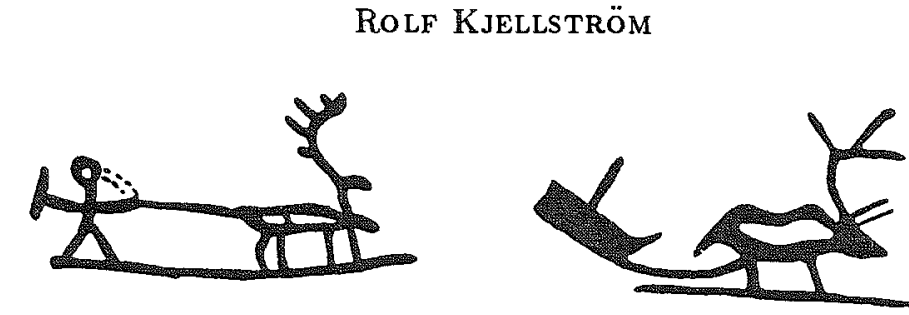

$\omega^{4}-\pi^{\pi}$

3tu jutip

Fig 5 Sleeghs drawn by rendeer
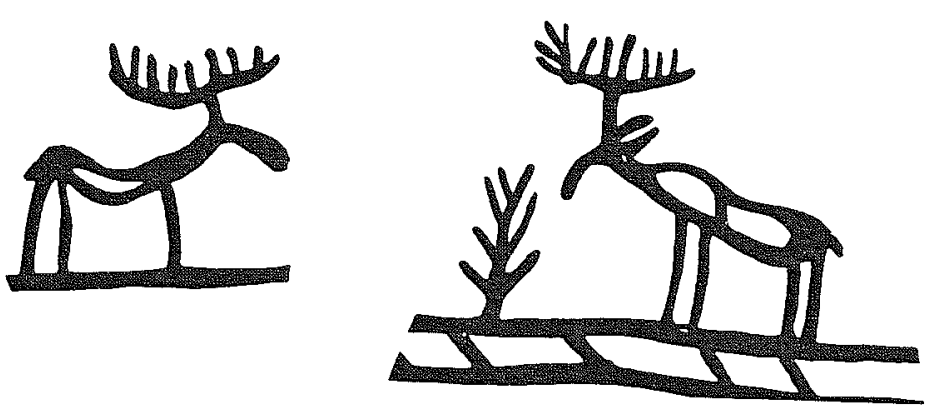

㸺

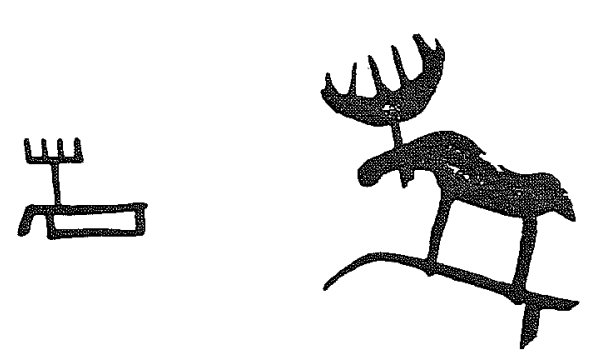

Fig 6 Elk 


\section{Elk figures on the drums (Fig 6)}

It has been possible to identify elks on half of the southern Saami drums It may be mentioned, moreover, that on Saami drums from other areas elks hardly occur at all - with only one exception As a drum motif, therefore, the elk is a clearly southern phenomenon, and it is possible that this picture of the animal's distribution corresponds to the actual distribution at the time when the drums onginated

The elk figures are often naturalistically portrayed and very convincingly drawn Even if the figure is done schematically, the bull in particular is easy to identify

The elk figure is often placed on the upward pointing ray of the sun sign, but also out on the left hand edge of the drum

The 33 elk figures identified are distributed as follows on the drum: on field no 120 ; on field no $2: 7$, on field no 3 : 6 ; on field no 4: 0 With another criterion of distribution, this means 26 animals in the left half against only seven in the right No animal appears in the bottom right-hand corner

\section{Bears}

We now move on to the bear The commonest method of hunting the bear was probably to discover in the autumn where the bear had gone to hibernate, in order to return later in the spring and take the bear in or around his lair The importance of the bear hunt for the Lapps is well documented and quite familiar, and I do not therefore think it is worth $d$ welling on the hunt and all the customs that have been connected with it As is well known, the bear has occupied a central position not only in the conceptual world of the Saamis, but also in that of other arctic peoples

Among the different kınds of Saamı hunts, that for the bear was accorded the greatest status, and talented bear hunters had a high reputation It has also been fairly widely practised I shall mention a minor detail with a personal connection: I own a modest little hut at the foot of Löfjället in Tärna parısh Of the few hunters that lived in that area in the 19 th century, Ol Sjulsson killed about 90 bears and Kristoffer Sjulsson's father, Lång Sjul Larsson, 83 bears Kristoffer Sjulsson himself killed 26 bears This perhaps gives an idea of the extent of bear huntıng

Regarding the incidence of bears on the drums, Manker's and my own interpretations differ considerably Whereas Manker finds that after the reindeer, the bear is the commonest figure on the drums, 

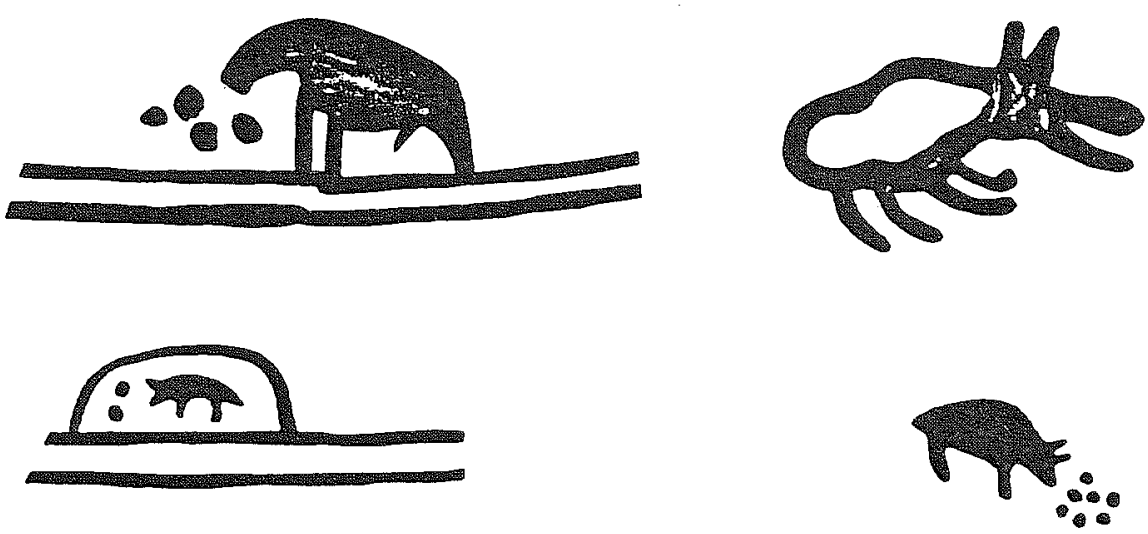

Fig 7 Bear
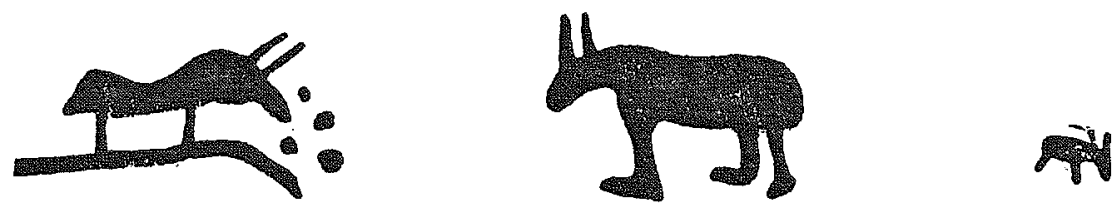

Fig 8 Figures described by Manker as bear figures

I have only been able to identify three figures as bears The reader himself can obtain an idea of the problem by examining figs 7 and 8 Two things should be born in mind when comparing my interpretations with those of Manker: firstly, how the animals have been drawn; and secondly, how they are combined with other objects portrayed

As far as appearances are concerned, many of the figures identified by Manker as bears have something like protruding ears or horns, which make it more reasonable to suppose that we are dealing with cattle, if one must guess at all I cannot in any case identify them as bears

The second point concerns a number of black dots - ranging from two to almost a dozen - which are often to be found in front of the muzzle of Manker's bear figures These dots have been given different interpretations, but Manker has plumped for that of Lybecker, that they represent berries, the bear's food 
Against this interpretation one could say a great deal, but I will limit myself to the point that - if there is any kind of proportion between these so called blueberries and the bear - then the berries must have been very large ones

It is quite clear to me that Manker has had a tendency to interpret all figures with these spots in front of them as bears, since this solution presented itself for one particular drum

\section{Wolves}

The wolf hunt

The wolf was an animal feared and hated by the Saamı if not actually regarded as despicable, but the wolf hunt was not thought to be as honourable as the bear hunt The wolf posed a threat both to the domesticated reindeer and to domestic cattle in general The Saamis, in particular, were regarded as good wolf hunters In these wolf hunts an almost unbelievable persistence and toughness were required, together with courage In general, the animal was pursued under snow conditions which favoured the skier rather than the wolf These hunts could go on for days and perhaps weeks Often several people cooperated, so that one was in front on the trail, whilst others were so called sack bearers

There is every reason to believe that the wolf hunt held great interest for the Saamis

\section{Wolves on the drums (Fig 9)}

If we turn to the drums, the wolf is often characteristically drawn with big ears and exaggeratedly large jaws

The wolf was one of the commoner figures and occurs on southern Saamı drums with 14 figures They feature above all in the lower half, in fields 3 and 4 , and only one figure is found in field 2 , but no figure in field 1 The majority defintely occur in field 4 

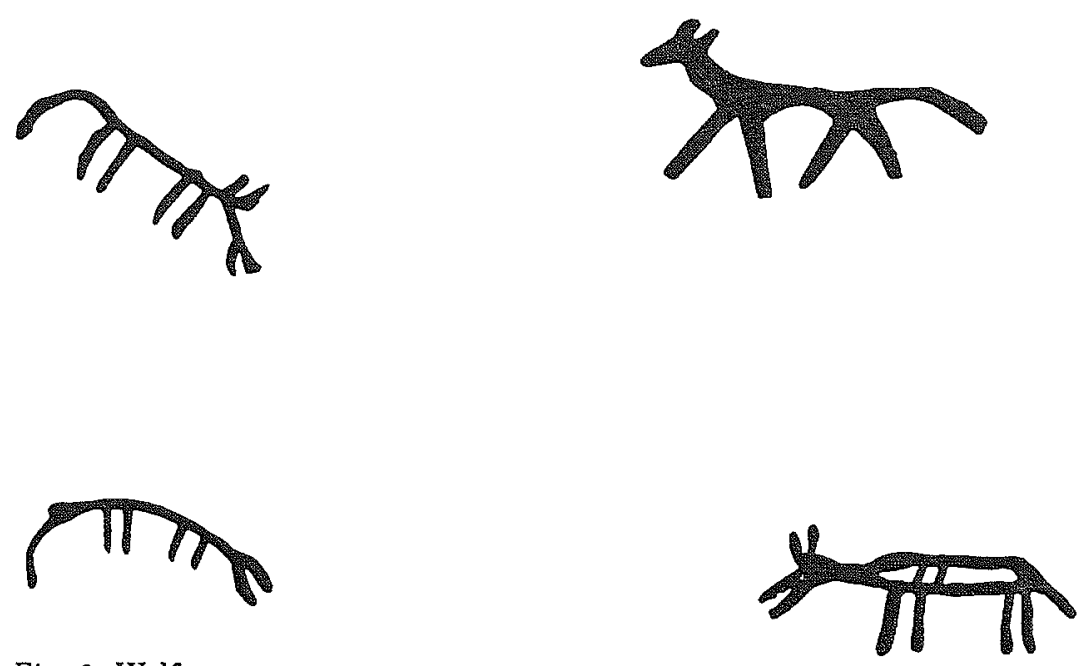

Fig 9 Wolf

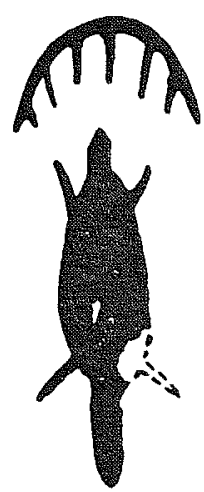

Fig 10 Beaver

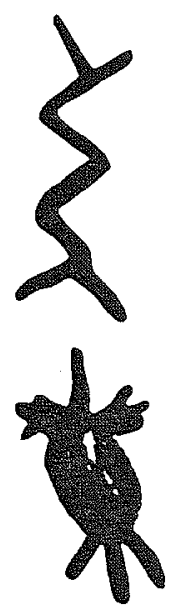

\section{Beavers}

The beaver was a particularly sought after quarry for some time Above all, it was the beaver "milk", the gland secretion, that was desirable The beaver was caught by the Saamis in nets or in pots

I have not, however, been able to find anything on the drums corresponding to the economic importance that the beaver must have had On the drums in question I can only identify two figures as beavers with any certainty, and it is these which can be seen in the figure (Fig 10) 

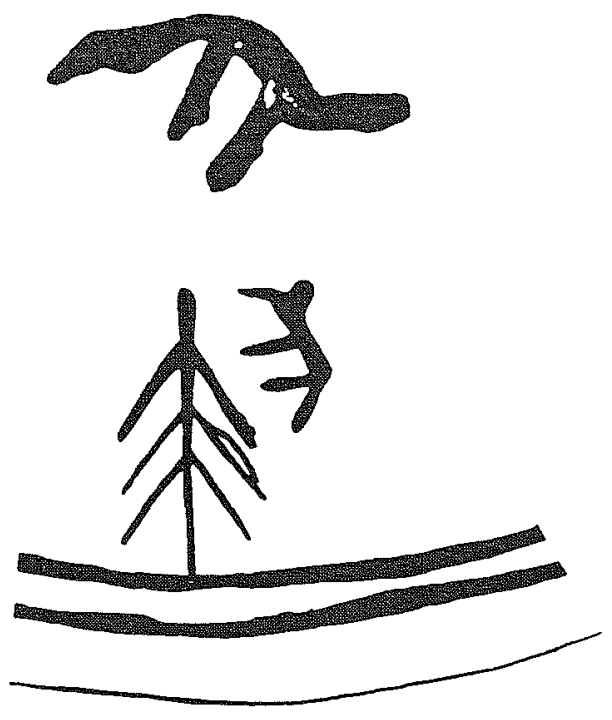
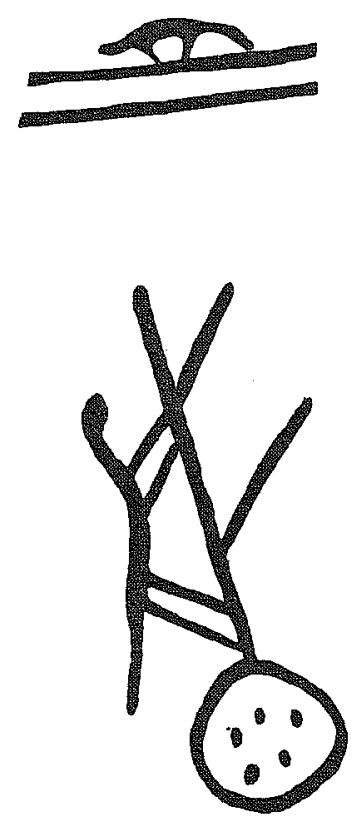

Fig 11 Wolverine, marten etc

\section{Wolverines (Fig 11)}

The wolverine is regarded by the Lapps as a particularly contemptible animal

This anımal was regarded as crafty, and it also spread a most intolerable smell when chased by dogs

Furthermore, the meat was seldom eaten The wolverine was there fore killed above all for reasons of prevention, in order to keep the reindeer in pease

The normal method of hunting for the Saamıs was to skı after it and club it to death But wolverines were also caught in wolverıne traps or killed in so called spear gins

To distinguish the wolverine on the drum is not so easy, and con fusion may occur, for example, with bears or other predators I have only been able to find one in my material 


\section{Martens}

Martens were keenly hunted by the Saamis and the implements used were nets, whuch they took with them on their trips

It is difficult if not 1mpossible to establish clearly the incidence of the marten on southern Saam drums, but it is possible that it could be one of the figures occurring there

\section{Foxes}

The fox probably had little importance for the reindeer-herding Saamı The fox was not edible game and it was no major threat to the reindeer either For those Saamis who devoted themselves to hunting, however, fox hunting was economically rewarding as the skins were often highly prized

On the drum there are three figures which $I$ understand to be foxes (Fig 12)
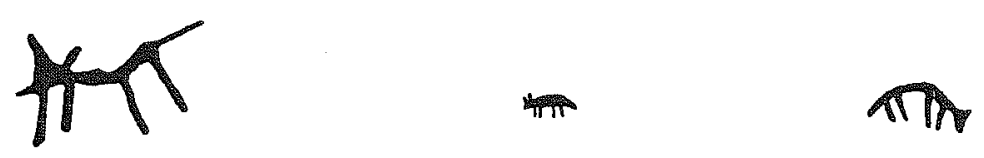

Fig 12 Fox

Fig 19 Lynx

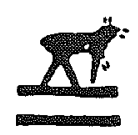

\section{Lynxes}

The lynx was hunted by the Saamıs, for example, by tracking On the drums I have only been able to identify one lynx figure (Fig 13)

\section{Snakes}

The snake or the zig zag pattern is discussed in greater detail elsewhere in this volume, and $\mathbb{I}$ therefore limit myself to mentioning that the drums contain twenty two figures of this type, of which twenty-one that is, all but one - occur on the left hand half of the drum It is thus a figure which occurs farrly frequently (Fig 14) 

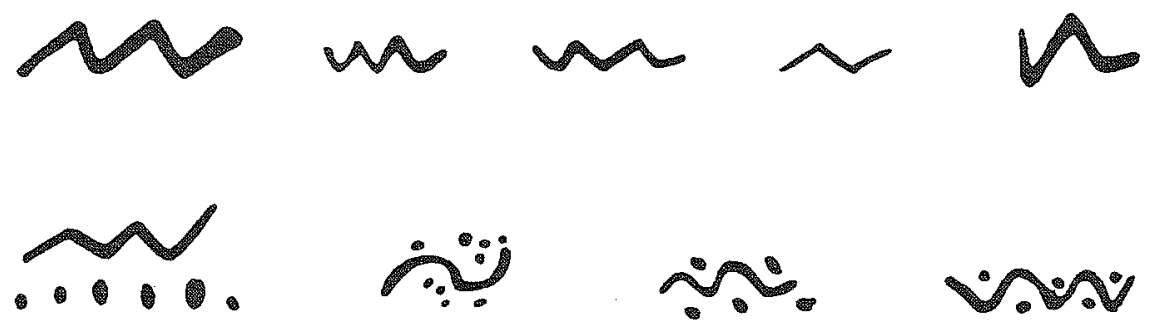

Fig 14 Snake
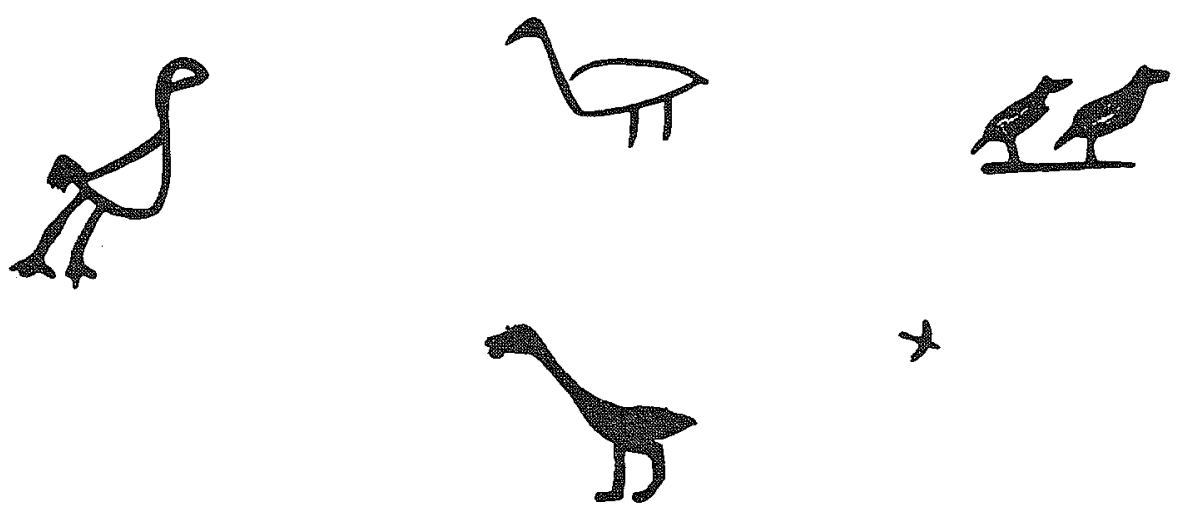

$x$

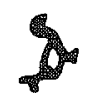

Fig 15 Birds
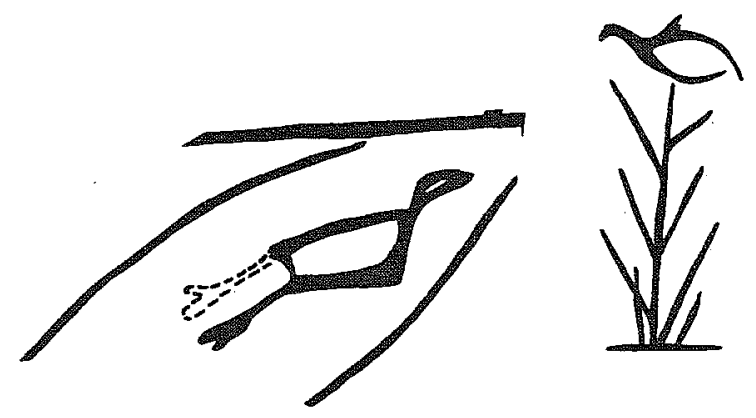

Birds

The Saamı hunted birds, above all moreland birds, 1 e capercaillie, black grouse and hazel grouse, as well as ptarmigan and sea birds The most important device for catching them was a trap made of tendons, which were later replaced by other material The diver was caught with nets Egg covering was practised

Birds are represented on the drums (Fig 15) by edible forest birds, but also by sea birds as well as goose and crane In the material I have been able to find seven birds, of which all but one appear on the left half of the drum 

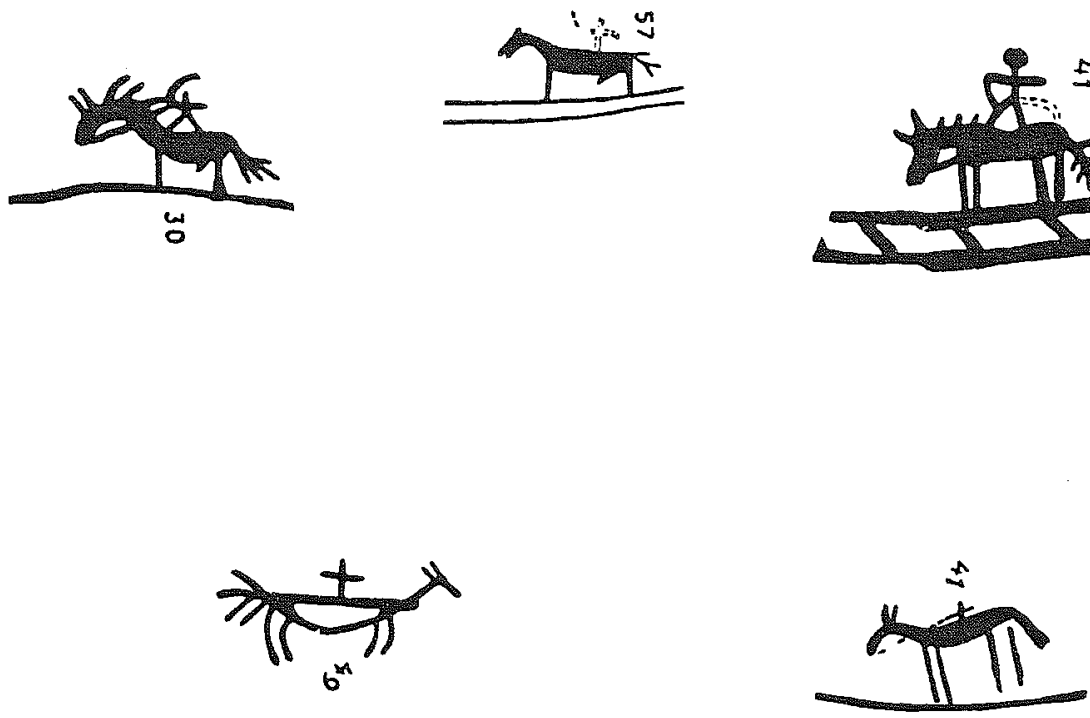

Fig 16 Horse

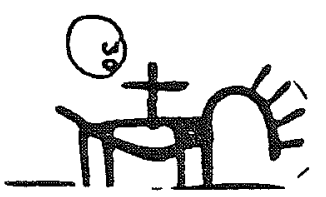

Fig 17 Horse according to Manker's interpretation

\section{Unknown animals}

A number of anımals could not be identified at all As far as position is concerned, they appear in all four fields and there are, all told, no less than sixty two examples Manker has defined several of these figures unknown to me as "noid anımals" or "saivo anımals"

\section{Domestic animals Horses}

Of the domesticated animals, we shall first mention the horse (Fig 16) This figure occurs in twenty nine cases

All of these occur in the second field and have roughly the same position: on the edge up towards the right of the drum

Manker has a few more examples on what he thinks might be horses (Fig 17) 
Goats

The goat is another domestic animal (Fig 18) Of this anımal we have an estımated twenty-five examples Like the horse, the goat also has its own position: over four fifths occur in field 2
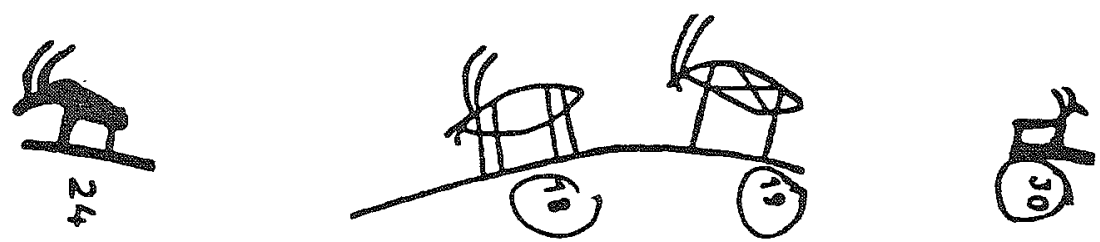

Fig 18 Goat

\section{Cattle}

With cattle there is some uncertainty. Manker has often characterised animals with horns as bears, which I find difficult to accept If my calculations are correct, most of these are in field 1 , but there are also some in fields 2 and 3 , although none in 4

\section{Dogs}

The dog occurs occasionally on the drums and is so well reproduced that one can even speculate as to what breed it is (Fig 19)

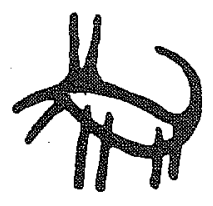

$12: 15$

Fig 19 Dog 


\section{Summary of the incidence of animals on the drum}

If one tries to distinguish the certain domestic anımals and begins with reindeer, horse and goat, one may state as follows: there are five anımals in field 1 , no animals in field 3 , seven anımals in field 4 In field 2 there are no less than fifty five, 1 e $82 \%$

If we exclude reindeer from this material and only consider goat + horse, there are fifty in field $2(=92 \%)$ and $4 \%$ in fields 1 and 3 respectively, and of course still $0 \%$ in field 3

If we examine the complete animal material, we thus find:

$\begin{array}{lrl}\text { In the centre: } & 2 \% & \text { In field 1 } 32 \%\end{array}$ In field 2: $23 \%$

I have mentioned the different positions of the animals above because I presume that historians of religion may have some help from this in their interpretation of the drum's symbolism

\section{Weapons on the drum and in reality}

Finally, a few words about the Saamis' hunting weapons The most important of these were the bow and arrow, and the spear or spear shaft Of these weapons it is the bow which is most often portrayed on drums (see Fig 20) and this weapon seems to have been used in hunting both large and small animals Later came the crossbow but there is no certain evidence of the use of this weapon found on drums

The sticks or staves that can sometimes be seen in connection with the portrayal of human figures may very well be spears or stick-spears - that 1s, an implement which was both skl-stick and weapon

How the split tip on the sticks or the spear is to be explanned I don't know, and I don't have any good suggestions et ther The only thing I can imagine, if one bears in mind that we are dealing with a weapon, is that it might be a horn protector for the spear edge The occurrence of a split arrow is easier to explain 

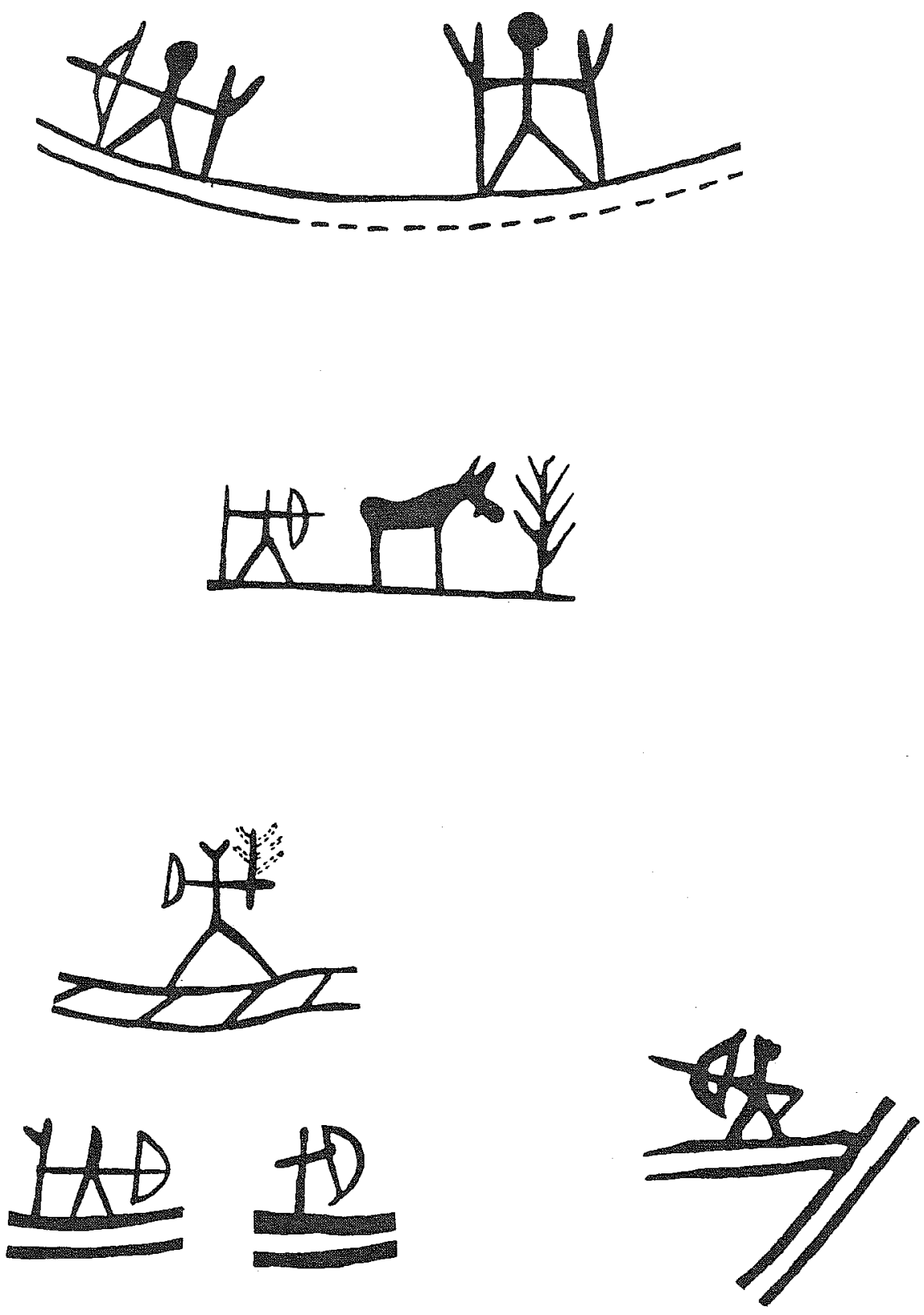

Fig 20 Weapons 


\section{Summary of catching methods}

Some trapping implement like a gin may appear on a drum But in general we have little or no information about hunting or trapping methods at all As has been apparent from this lecture the drums contain greater numbers of pictures of animals assumed to have played an important part in the conceptual world of the Saamis, such as the domestic cattle of neighbouring peoples, predators, the elk and above all - the reindeer

\section{Bibliography}

Drake, S 1918 Västerbottenslapparna under förra hälften av 1800-talet (Lapparna och deras land 7 ) Uppsala

Ekman, S 1910 Norrlands jakt och fiske Uppsala

Henriksson, H 1976 Folklig jakt och fängst i Norrland Ms

Kjellström, R 1989 Jakt och fängst थ norr Ms

Lundi[us], N 1905 Nicolaı Lundii Lappı descrıptio Lapponıa Utg av $\mathrm{K}$ B. Wiklund Bidrag till kännedom om de svenska landsmålen och svenskt folkliv 17, 5 Uppsala

Manker, E 1950 Die lappische Zaubertrommel 2 (Acta Lapponica 6 ) Stockholm

Niurenuus, O P 1905 Lappland eller beskrivning över den nordiska trakt, som lapparne bebo [ ] Utg av K B Wiklund Bidrag till kännedom om de svenska landsmälen och svenskt folkliv 17, 4 Uppsala

Pettersson, O P 1979 Kristoffer Sjulssons minnen [Ed by] L Bäckman \& R Kjellström (Acta Lapponıca 20 ) Stockholm

Zetterstedt, J W 1980 Resa genom Umeå lappmarker ¿ Vesterbottens län Sec ed Umeå 